\title{
Optimal reconstruction of measurements in electrical power transmission and distribution systems
}

\author{
Fermín Cabezas Soldevilla, Mechanical - Electrical Engineer ${ }^{1}$, Franklin Cabezas Huerta, Electronic Engineer ${ }^{2}$ \\ ${ }^{1}$ Universidad Nacional de Ingeniería, Peru, fcabezass@uni.edu.pe \\ ${ }^{2}$ Universidad Nacional de Ingeniería, Peru, fcabezash@uni.pe
}

\begin{abstract}
In the transmission and distribution systems there are very important activities such as: planning, design, operation, maintenance and commercialization, which are based on the knowledge with good precision of its operation variables: active powers, reactive powers and phasor voltages.

Misleading values of these variables distort the mentioned activities and can cause serious technical, economic and social consequences. The measurements of these variables are made in the bars of the lines by a chain of processes, where each of them introduces an error to the measurement. The power measurement errors are usually large, of the order of 3 or $4 \%$. In the measurements of each line, anomalous or absent measurements are detected in many intervals of each month, mainly due to the indicated limitations and temporary failures in the meters. In the present work a method of calculation for the detection, identification and reconstruction of absent and anomalous measurements in the national system of electrical transmission is proposed and developed through the use of state estimation techniques and estimation of parameters based on least squares and the equations of charge flow of the lines, using all the measurements of active energies, reactive energies and existing tensions in the fifteen minute intervals, in both ends of the lines corresponding to the month in which their evaluation is carried out. The application of the proposed method to the $220 \mathrm{KV}$ Chimbote Trujillo line for a sub set of 21 data rows vectors from a total of 2880 data row vectors corresponding to its July 2018 operation is presented.
\end{abstract}

Keywords-- abnormal measurements, state estimation, Chi square distribution, estimation error, parameter estimation.

\section{INTRODUCTION}

The best way to verify the quality of the measurements of the operation variables is to determine if their values meet the equations of the power flows model of the transmission lines (which depends on their state variables and their physical parameters), if the error is small the measurements are acceptable, otherwise it will be necessary to reconstruct them in an optimal way. However the equations of the model cannot be used directly because it is necessary to know with good accuracy the values of the state variables such as voltages and phase angles: $V_{1}, V_{2}, \delta$ and also of their physical parameters, such as resistances, reactances, inductances, capacitive reactances and perditances or leak admittances: $R, X_{L}, Y_{C}, Y_{R}$.

Because of this, it will be necessary to use optimal estimation techniques to find the optimal estimated values of the state variables and physical parameters [1], [5], [7], [8], [9], [10] and with these find the optimal estimated values of the power flows using the equations of the power flow model.

Digital Object Identifier (DOI):

http://dx.doi.org/10.18687/LACCEI2019.1.1.468

ISBN: 978-0-9993443-6-1 ISSN: 2414-6390
If the estimation errors of the power flows are large with respect to their corresponding measured values, this means that the corresponding measurements are abnormal and will be optimally reconstructed [5], which is the objective of the present work.

\section{PROBLEM FORMULATION}

\section{A. Load Flow Equations by Phase with the PI model}

If the Kirchhoff equations are applied to the circuit of the PI model in bars 1 and 2 and in the loop between them, the equations 1 to 4 are obtained, which correspond to the load flow of a transmission line [6]:

$$
\begin{aligned}
& P_{1}=\left|V_{1}\right|^{2} Y_{R}+\frac{\left|V_{1}\right|^{2} R}{R^{2}+X_{L}^{2}}-\frac{\left|V_{1}\right|\left|V_{2}\right| R \cos \delta}{R^{2}+X_{L}^{2}}-\frac{\left|V_{1}\right|\left|V_{2}\right| X_{L} \sin \delta}{R^{2}+X_{L}^{2}} \\
& Q_{1}=-\left|V_{1}\right|^{2} Y_{C}+\frac{\left|V_{1}\right| V_{2} \mid R \sin \delta}{R^{2}+X_{L}^{2}}+\frac{\left|V_{1}\right|^{2} X_{L}}{R^{2}+X_{L}^{2}}-\frac{\left|V_{1}\right|\left|V_{2}\right| X_{L} \cos \delta}{R^{2}+X_{L}^{2}} \\
& P_{2}=\left|V_{2}\right|^{2} Y_{R}+\frac{\left|V_{2}\right|^{2} R}{R^{2}+X_{L}^{2}}-\frac{\left|V_{1}\right|\left|V_{2}\right| R \cos \delta}{R^{2}+X_{L}^{2}}+\frac{\left|V_{1}\right|\left|V_{2}\right| X_{L} \sin \delta}{R^{2}+X_{L}^{2}}
\end{aligned}
$$

$Q_{2}=-\left|V_{2}\right|^{2} Y_{C}+\frac{\left|V_{2}\right|^{2} X_{L}}{R^{2}+X_{L}^{2}}-\frac{\left|V_{1}\right|\left|V_{2}\right| R \sin \delta}{R^{2}+X_{L}^{2}}-\frac{\left|V_{1}\right|\left|V_{2}\right| X_{L} \cos \delta}{R^{2}+X_{L}^{2}}$

State variables:

$\mathrm{V}_{1}, \mathrm{~V}_{2} \quad$ Line voltages (in $\mathrm{kV}$ ) in bars 1 and 2.

$\mathrm{d}_{1}, \mathrm{~d}_{2} \quad$ Phase angles (radians) of the voltages with respect to a reference.

$d=d_{1}-d_{2}$ Relative phase shift (radians) of voltages.

Operation variables:

$\mathrm{P}_{1}, \mathrm{P}_{2} \quad$ Active line powers (in MW) in bars 1 and 2

$\mathrm{Q}_{1}, \mathrm{Q}_{2}$ Reactive line powers (in MVAR) in bars 1 and 2

Physical parameters:

$\mathrm{R} \quad$ Resistance (ohm) (resistive effect)

$\mathrm{X}_{\mathrm{L}} \quad$ Inductive reactance (ohm) (inductive effect)

$\mathrm{Y}_{\mathrm{C}} \quad$ Capacitive susceptance (Mho) (capacitive effect)

$17^{\text {th }}$ LACCEI International Multi-Conference for Engineering, Education, and Technology: "Industry, Innovation, And Infrastructure for Sustainable Cities and Communities", 24-26 July 2019, Jamaica. 
$Y_{R}$

Leakage conductance or perditance (Mhos or Siemens) (effect of current leakage to the outside environment)

B. Analytical development of the estimation process of state and physical parameters

The optimal estimation process is presented in Fig. 1 where in each measurement interval $\mathrm{k}$, the output vector $\mathbf{Z}$ of the real system is compared with the output vector $\mathbf{Y}$ of the model.

If the error $\mathbf{J}$ is large, the optimal corrections $\mathbf{d p}, \mathbf{d x}$ are calculated and with these, the new values $\mathbf{p}, \mathbf{x}$ and $\mathbf{Y}$ are calculated for the next interval $\mathrm{k}+1$. This comparison and correction process is continued iteratively until the magnitude of the error is lower than the allowed error values, thus obtaining the optimal $\mathbf{x}$ of the state variables and the optimal identification $\mathbf{p}$ of the physical parameters.

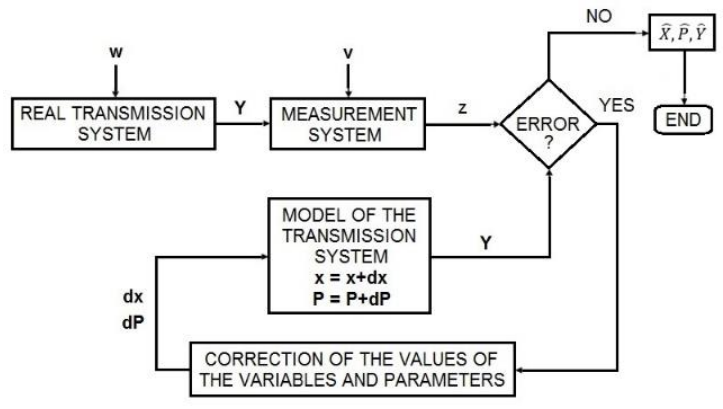

Fig. 1 Optimal state estimation and identification of physical parameters.

A natural function of the quadratic error of estimation of state and of physical parameters [3] for the whole system, pondering the quality of the meters and the distrust of the initial vector of physical parameters is:

$$
\begin{gathered}
J(x(k), k=1 \ldots N ; p)= \\
=\left(\sum_{k=1}^{N}[z(k)-f(x(k), p)]^{T} R^{-1}[z(k)-f(x(k), p)]\right) \\
+\left(p^{0}-p\right)^{T} M^{-1}\left(p^{0}-p\right)
\end{gathered}
$$

The process of state estimation and identification of physical parameters consists of finding the set of optimal estimated vectors of state $\mathrm{x}(\mathrm{k}), \mathrm{k}=1 \ldots \mathrm{N}$ and the vector of physical estimated parameters $\mathrm{p}$ to minimize $\mathrm{J}$.

It is observed that the value of estimated $\mathrm{p}$ is constant for all the estimated vectors $\mathrm{x}(\mathrm{k}), \mathrm{k}=1 \ldots \mathrm{N}$. The following symbology will be used: $\mathrm{k}=1,2, \ldots . . \mathrm{k}$........ .

It is a generic time interval of 15 minutes in which measurements are taken.

$\mathrm{N}$ is the total number of intervals in the time series. In this case, taking into account that the measurement vectors are made every 15 minutes, for a month the value is the following:

$$
\begin{gathered}
N=\left(\frac{4 \text { measurement vectors }}{\text { hour }}\right)\left(\frac{24 \text { hours }}{\text { day }}\right)\left(\frac{30 \text { days }}{\text { month }}\right) \\
=2880 \text { measurement vectors }
\end{gathered}
$$

$\mathbf{x}(\mathrm{k}) \quad$ State vector, $x=\left[\begin{array}{lll}V_{1} & V_{2} & \delta\end{array}\right]^{T}$

p Vector of physical parameters, $\mathrm{p}=\left[\mathrm{R} \mathrm{Y}_{\mathrm{R}} \mathrm{X}_{\mathrm{L}} \mathrm{Y}_{\mathrm{C}}\right]^{\mathrm{T}}$

$\mathbf{p}^{0} \quad$ Vector of values of nominal or initial physical parameters

$\mathbf{y}(\mathbf{k})=\mathbf{f}(\mathbf{x}(\mathrm{k}), \mathbf{p}, \mathrm{k})$ Vector of calculated operating variables: active, reactive powers and voltages

$\mathbf{z}(\mathrm{k}) \quad$ Vectors of measured operating variables

$\mathbf{v}(\mathrm{k}) \quad$ Deviation vector or error of the measured values of the operating variables with respect to their calculated values

$\mathbf{R}(\mathrm{k}) \quad$ Covariance matrix of the vector $\mathbf{v}(\mathrm{k})$ or quality matrix of the meters. It is usually a diagonal matrix and represents the squares of the standard deviations of the measurements

w Deviation vector of the current physical parameters with respect to the initial physical parameters

M Covariance matrix of the $\mathbf{w}$ vector or matrix of mistrust of the initial parameters

In each measurement interval $\mathrm{k}$, the relationship between the measured values $\mathbf{z}(\mathrm{k})$ of the operating variables and their calculated values $\mathbf{f}(\mathbf{x}(\mathrm{k}), \mathbf{p}, \mathrm{k})$ is represented by :

$$
\mathbf{v}(\mathrm{k})=\mathbf{z}(\mathrm{k})-\mathbf{f}(\mathbf{x}(\mathrm{k}), \mathbf{p}, \mathrm{k}
$$

C. Identification of physical parameters using optimization by Newton Raphson

This optimization method is shown in Fig. 2, which is very efficient, tested and used by state estimation processes of most control centers in the world, Kusic [1], Wood [2], Stevenson [5]. Its use in parameter estimation was initially proposed by Debs [3] and Schweppe [4].

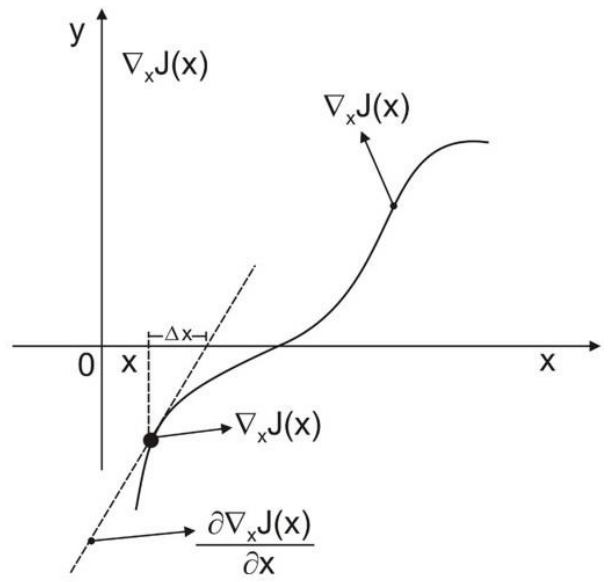

Fig. 2 Method of successive approximations applying Newton Raphson in successive linear sections.

$17^{\text {th }}$ LACCEI International Multi-Conference for Engineering, Education, and Technology: "Industry, Innovation, And Infrastructure for Sustainable Cities and Communities", 24-26 July 2019, Jamaica. 
The form and details of how the identification of parameters using Newton Raphson used in this work is described in Fig. 3 [6]

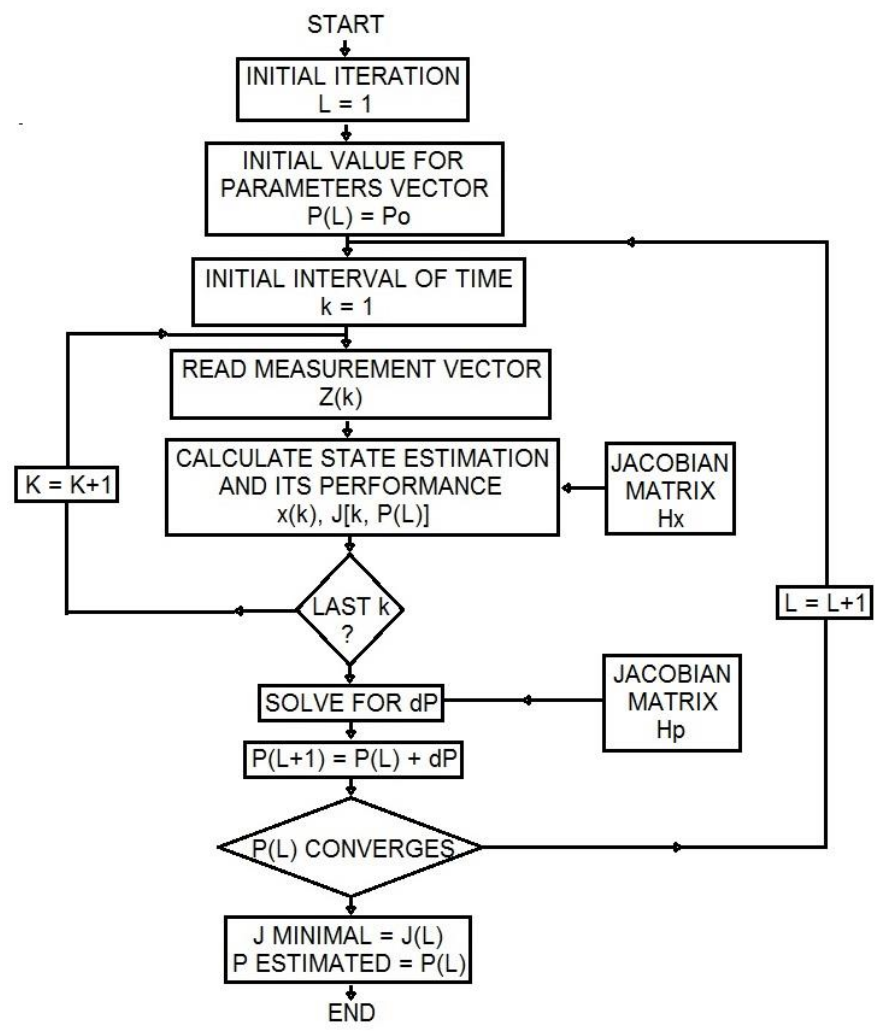

Fig. 3 Identification of parameters using Newton Raphson.

Using the method of successive linear approximations and the Newton Raphson method [6] the optimal correction for the vector of physical parameters are obtained:

$$
\begin{gathered}
d p_{L}=\left\{\sum_{k=1}^{N}\left[H_{P}^{T}(k) R^{-1} H_{p}(k)\right]+M^{-1}\right\}^{-1} \\
\left\{\sum_{k=1}^{N} H_{P}^{T}(k) R^{-1}\left[z(k)-y\left(x(k), p_{L}\right)\right]+M^{-1}\left(p^{0}-p_{L}\right)\right\}(7)
\end{gathered}
$$

The Jacobian Hx of $f(x)$ with respect to the state variable is made up by the following set of equations:

$$
\begin{gathered}
\frac{\partial P_{1}}{\partial V_{1}}=2 \mathrm{Y}_{\mathrm{R}} \mathrm{V}_{1}+\left(2 \mathrm{RV}_{1}-\mathrm{RV}_{2} \cos \delta+\mathrm{X}_{\mathrm{L}} \mathrm{V}_{2} \operatorname{sen} \delta\right)\left(\frac{1}{R^{2}+X_{L}^{2}}\right) \\
\frac{\partial P_{1}}{\partial V_{2}}=\left(-\mathrm{RV}_{1} \cos \delta+\mathrm{X}_{\mathrm{L}} \mathrm{V}_{1} \operatorname{sen} \delta\right)\left(\frac{1}{R^{2}+X_{L}^{2}}\right) \\
\frac{\partial P_{1}}{\partial \delta}=\left(\mathrm{RV}_{1} \mathrm{~V}_{2} \operatorname{sen} \delta+\mathrm{X}_{\mathrm{L}} \mathrm{V}_{1} \mathrm{~V}_{2} \cos \delta\right)\left(\frac{1}{R^{2}+X_{L}^{2}}\right) \\
\frac{\partial Q_{1}}{\partial V_{1}}=-2 \mathrm{Y}_{\mathrm{C}} \mathrm{V}_{1}+\left(2 \mathrm{X}_{1} \mathrm{~V}_{1}-\mathrm{RV}_{2} \operatorname{sen} \delta-\mathrm{X}_{\mathrm{L}} \mathrm{V}_{2} \cos \delta\right)\left(\frac{1}{R^{2}+X_{L}^{2}}\right) \\
\frac{\partial Q_{1}}{\partial V_{1}}=\left(-\mathrm{RV}_{1} \operatorname{sen} \delta+\mathrm{X}_{\mathrm{L}} \mathrm{V}_{1} \cos \delta\right)\left(\frac{1}{R^{2}+X_{L}^{2}}\right)
\end{gathered}
$$

$$
\begin{gathered}
\frac{\partial Q_{1}}{\partial \delta}=\left(-\mathrm{RV}_{1} \mathrm{~V}_{2} \cos \delta+\mathrm{X}_{\mathrm{L}} \mathrm{V}_{1} \mathrm{~V}_{2} \operatorname{sen} \delta\right)\left(\frac{1}{R^{2}+X_{L}^{2}}\right) \\
\frac{\partial V_{1}}{\partial V_{1}}=1 \\
\frac{\partial V_{1}}{\partial V_{2}}=0 \\
\frac{\partial V_{1}}{\partial \delta}=0 \\
\frac{\partial P_{2}}{\partial V_{2}}=2 \mathrm{~V}_{2} \mathrm{Y}_{\mathrm{R}}+\left(2 \mathrm{~V}_{2} \mathrm{R}-\mathrm{R} \mathrm{V}_{1} \cos \delta-\mathrm{X}_{\mathrm{L}} \mathrm{V}_{1} \operatorname{sen} \delta\right)\left(\frac{1}{R^{2}+X_{L}^{2}}\right) \\
\frac{\partial P_{2}}{\partial \delta}=\left(\mathrm{RV_{1 }} \mathrm{V}_{2} \operatorname{sen} \delta-\mathrm{X}_{\mathrm{L}} \mathrm{V}_{1} \mathrm{~V}_{2} \cos \delta\right)\left(\frac{1}{R^{2}+X_{L}^{2}}\right) \\
\frac{\partial Q_{2}}{\partial V_{1}}=\left(\mathrm{RV_{2 } \operatorname { s e n } \delta}-\mathrm{X}_{\mathrm{L}} \mathrm{V}_{2} \cos \delta\right)\left(\frac{1}{R^{2}+X_{L}^{2}}\right) \\
\frac{\partial Q_{2}}{\partial V_{2}}=-2 \mathrm{Y}_{\mathrm{C}} \mathrm{V}_{2}+\left(2 \mathrm{X}_{1} \mathrm{~V}_{2}+\mathrm{RV} \mathrm{V}_{1} \operatorname{sen} \delta-\mathrm{X}_{\mathrm{L}} \mathrm{V}_{1} \cos \delta\right)\left(\frac{1}{R^{2}+X_{L}^{2}}\right) \\
\frac{\partial Q_{2}}{\partial \delta}=\left(\mathrm{RV} \mathrm{V}_{2} \cos \delta+\mathrm{X}_{\mathrm{L}} \mathrm{V}_{1} \mathrm{~V}_{2} \operatorname{sen} \delta\right)\left(\frac{1}{R^{2}+X_{L}^{2}}\right) \\
\frac{\partial V_{2}}{\partial V_{1}}=0 \\
\frac{\partial V_{2}}{\partial V_{2}}=1 \\
\frac{\partial V_{2}}{\partial \delta}=0
\end{gathered}
$$

The Jacobian Hp of $f(x)$ with respect to physical parameters is made up by the following set of equations:

$$
\begin{gathered}
\frac{\partial P_{1}}{R}=\frac{1}{\left(R^{2}+X_{L}^{2}\right)^{2}}\left(\left(\mathrm{X}_{L}^{2}-\mathrm{R}^{2}\right)\left(V_{1}^{2}-\mathrm{V}_{1} \mathrm{~V}_{2} \cos \delta\right)\right. \\
\left.-2 \mathrm{RX}_{\mathrm{L}} \mathrm{V}_{1} \mathrm{~V}_{2} \operatorname{sen} \delta\right) \\
\frac{\partial P_{1}}{\partial Y_{R}}=V_{1}^{2} \\
\frac{\partial P_{1}}{X_{L}}=\frac{1}{\left(R^{2}+X_{L}^{2}\right)^{2}}\left(-2 \mathrm{X}_{\mathrm{L}} \mathrm{R} \mathrm{V}_{1}^{2}+2 \mathrm{X}_{\mathrm{L}} \mathrm{RV_{1 }} \mathrm{V}_{2} \cos \delta\right. \\
\left.+\mathrm{V}_{1} \mathrm{~V}_{2} \operatorname{sen} \delta\left(\mathrm{R}^{2}-\mathrm{X}_{L}^{2}\right)\right) \\
\frac{\partial P_{1}}{Y_{C}}=0 \\
\frac{\partial Q_{1}}{R}=\frac{1}{\left(R^{2}+X_{L}^{2}\right)^{2}}\left(-2 \mathrm{RV}_{1}^{2} \mathrm{X}_{\mathrm{L}}-\left(\mathrm{X}_{L}^{2}-\mathrm{R}^{2}\right) \mathrm{V}_{1} \mathrm{~V}_{2} \operatorname{sen} \delta\right. \\
\left.+2 \mathrm{RX}_{\mathrm{L}} \mathrm{V}_{1} \mathrm{~V}_{2} \cos \delta\right) \\
\frac{\partial Q_{1}}{\partial Y_{R}}=0 \\
\frac{\partial Q_{1}}{\partial X_{L}}=\frac{1}{\left(R^{2}+X_{L}^{2}\right)^{2}}\left(\left(\mathrm{R}^{2}-\mathrm{X}_{L}^{2}\right)\left(\mathrm{V}_{1}^{2}-\mathrm{V}_{1} \mathrm{~V}_{2} \cos \delta\right)\right. \\
\left.+2 \mathrm{X}_{\mathrm{L}} \mathrm{RV}_{1} \mathrm{~V}_{2} \operatorname{sen} \delta\right) \\
\frac{\partial Q_{1}}{\partial Y_{C}}=-\mathrm{V}_{1}^{2}
\end{gathered}
$$

$17^{\text {th }}$ LACCEI International Multi-Conference for Engineering, Education, and Technology: "Industry, Innovation, And Infrastructure for Sustainable Cities and Communities", 24-26 July 2019, Jamaica. 


$$
\begin{aligned}
& \frac{\partial V_{1}}{\partial R}=0 \\
& \frac{\partial V_{1}}{\partial Y_{R}}=0 \\
& \frac{\partial V_{1}}{\partial X_{L}}=0 \\
& \frac{\partial V_{1}}{\partial Y_{C}}=0 \\
& \frac{\partial P_{2}}{\partial R}=\frac{1}{\left(R^{2}+X_{L}^{2}\right)^{2}}\left(\left(\mathrm{X}_{L}^{2}-\mathrm{R}^{2}\right)\left(\mathrm{V}_{2}^{2}-\mathrm{V}_{1} \mathrm{~V}_{2} \cos \delta\right)\right. \\
& +2 \mathrm{RX}_{\mathrm{L}} \mathrm{V}_{1} \mathrm{~V}_{2} \operatorname{sen} \delta \text { ) } \\
& \frac{\partial P_{2}}{\partial Y_{R}}=\mathrm{V}_{2}^{2} \\
& \frac{\partial P_{2}}{\partial X_{L}}=\frac{1}{\left(R^{2}+X_{L}^{2}\right)^{2}}\left(-2 \mathrm{X}_{\mathrm{L}} \mathrm{RV}_{2}^{2}+\mathrm{X}_{\mathrm{L}} \mathrm{R} \mathrm{V}_{1} \mathrm{~V}_{2} \cos \delta\right. \\
& \left.-\mathrm{V}_{1} \mathrm{~V}_{2} \operatorname{sen} \delta\left(\mathrm{R}^{2}-\mathrm{X}_{L}^{2}\right)\right) \\
& \frac{\partial P_{2}}{\partial Y_{C}}=0 \\
& \frac{\partial Q_{2}}{\partial R}=\frac{1}{\left(R^{2}+X_{L}^{2}\right)^{2}}\left(-2 \mathrm{RV}_{2}^{2} \mathrm{X}_{\mathrm{L}}+\left(\mathrm{X}_{L}^{2}-\mathrm{R}^{2}\right)\left(\mathrm{V}_{1} \mathrm{~V}_{2} \operatorname{sen} \delta\right)\right. \\
& +2 \mathrm{R} \mathrm{X}_{\mathrm{L}} \mathrm{V}_{1} \mathrm{~V}_{2} \cos \delta \text { ) } \\
& \frac{\partial Q_{2}}{\partial Y_{R}}=0 \\
& \frac{\partial Q_{2}}{\partial X_{L}}=\frac{1}{\left(R^{2}+X_{L}^{2}\right)^{2}}\left(\left(\mathrm{R}^{2}-\mathrm{X}_{L}^{2}\right)\left(\mathrm{V}_{2}^{2}-\mathrm{V}_{1} \mathrm{~V}_{2} \cos \delta\right)\right. \\
& \text { - } 2 \mathrm{X}_{\mathrm{L}} \mathrm{R} \mathrm{V}_{1} \mathrm{~V}_{2} \operatorname{sen} \delta \text { ) } \\
& \frac{\partial Q_{2}}{\partial Y_{C}}=-\mathrm{V}_{2}^{2} \\
& \frac{\partial V_{2}}{\partial R}=0 \\
& \frac{\partial V_{2}}{\partial Y_{R}}=0 \\
& \frac{\partial V_{2}}{\partial X_{L}}=0 \\
& \frac{\partial V_{2}}{\partial Y_{C}}=0
\end{aligned}
$$

D. Process for the detection, identification and reconstruction of absent and abnormal measurements in transmission lines

The normalized quadratic mean error $\mathrm{J}$, for each row of the database, is given by:

$$
\begin{aligned}
J= & \frac{\left(Z_{1}-P_{1}^{e s t}\right)^{2}}{\sigma_{1}^{2}}+\frac{\left(Z_{2}-Q_{1}^{e s t}\right)^{2}}{\sigma_{2}^{2}}+\frac{\left(Z_{3}-V_{1}^{e s t}\right)^{2}}{\sigma_{3}^{2}} \\
& +\frac{\left(Z_{4}-P_{2}^{e s t}\right)^{2}}{\sigma_{4}^{2}}+\frac{\left(Z_{5}-Q_{2}^{e s t}\right)^{2}}{\sigma_{5}^{2}}+\frac{\left(Z_{6}-V_{2}^{e s t}\right)^{2}}{\sigma_{6}^{2}}(50)
\end{aligned}
$$

where:

$Z=\left[Z_{1}, Z_{2}, Z_{3}, Z_{4}, Z_{5}, Z_{6}\right] \quad$ Row of measured values of the operating variables of a transmission line.

$f^{e s t}=\left[P_{1}^{e s t}, Q_{1}^{\text {est }}, V_{1}^{e s t}, P_{2}^{e s t}, Q_{2}^{e s t}, V_{2}^{\text {est }}\right] \quad$ Row of optimal estimated values

$\sigma_{i}^{2}$ are the variances corresponding to $z_{i}-f_{i}^{e s t}$

The $\mathrm{Z}_{\mathrm{i}}$ measurement of each of the operating variables has a normal probabilistic distribution (which corresponds approximately to the energy counters) as shown in Fig. 4. Likewise, the estimated values of the operating variables have the same normal distribution but its standard deviation is obviously smaller than that of the measured values as shown in Fig. 3.

According to the above, the errors of each of the measured variables with respect to their estimated values also have normal probabilistic distributions and the same occurs with the normalized errors as shown in Fig. 4.
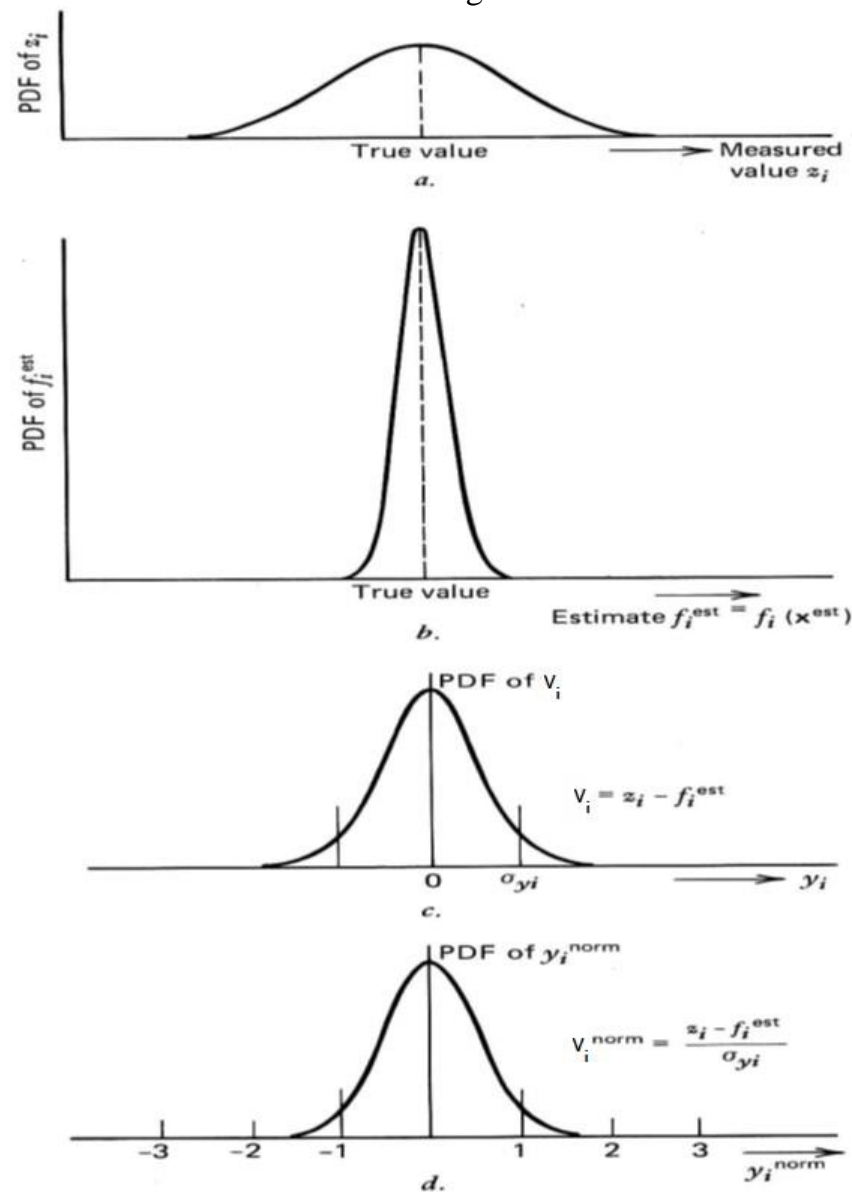

Fig. 4 Probability function of the normalized error $z_{i}^{\text {norm }}$ of the measurement with respect to its estimated value.

$17^{\text {th }}$ LACCEI International Multi-Conference for Engineering, Education, and Technology: "Industry, Innovation, And 
J has a Chi-Square $\chi^{2}(k)$, because each of its addends has a normal distribution [5].

This distribution for $\mathrm{k}$ degrees of freedom has a typical behavior, like the one shown in Fig. 5, where:

$k$ number of degrees of freedom

$\mathrm{J}_{\mathrm{MAX}}$ maximum allowed value (critical threshold) of the optimal estimation error $J(\hat{x})$

$\alpha$ area below the curve after $\mathrm{J}_{\mathrm{MAX}}$ that represents the probability that error $\mathrm{J}$ is greater than $\mathrm{J}_{\mathrm{MAX}}$ (level of mistrust).

$1-\alpha$ area below the curve before de $\mathrm{J}_{\mathrm{MAX}}$ that represents the probability that error $\mathrm{J}$ is less than $\mathrm{J}_{\mathrm{MAX}}$ (confidence level). Also prob $\left(J(\hat{x})<J_{M A X}\right)=1-\alpha$

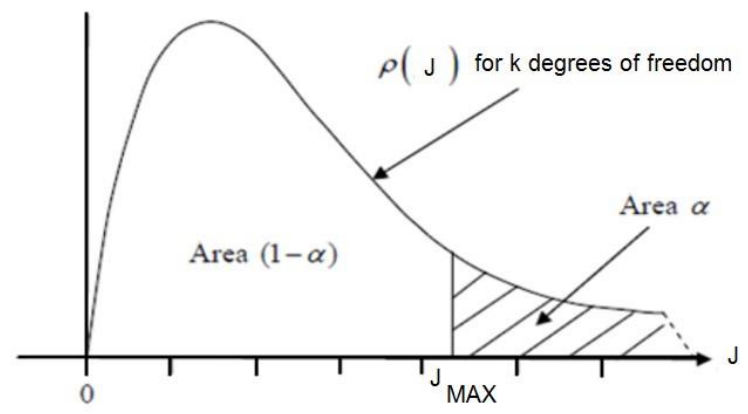

Fig. 5 Probability density function of the estimation error $\mathrm{J}$ with Chi - Square distribution.

These characteristics are tabulated in tables as Table 1 that shows the relationship between $\mathrm{k}, \mathrm{J}_{\mathrm{MAX}}$ and $\alpha$ in the ChiSquare function.

TABLE 1

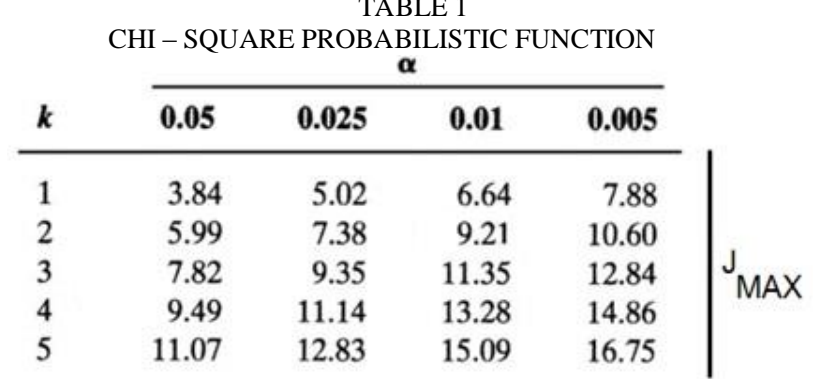

E. Determination of the maximum allowed value of the estimation error of the operation variables of the transmission lines

A confidence of de $99 \%$ means that $1-\alpha=0.99$ where $\alpha=0.01$. With six measurements $(\mathrm{Nm}=6)$ and three state variables $(\mathrm{Ns}=3)$ we obtain $\mathrm{k}=\mathrm{Nm}-\mathrm{Ns}=3$ (degrees of freedom of the line), and entering Table 2.3 with $\mathrm{k}=3$ and $\alpha=0.01$ the threshold Jmax $=11.35$ is found.
Similarly, with five measurements we obtain $\mathrm{k}=\mathrm{Nm}-\mathrm{Ns}$ $=2$, and entering the table with $\mathrm{k}=2$ and $\alpha=0.01$, we find the threshold Jmax $=9.21$ and with four measurements we obtain $\mathrm{k}=\mathrm{Nm}-\mathrm{Ns}=1$ and entering to the table with $\mathrm{k}=1$ and $\alpha=0.01$, we find the threshold $\operatorname{Jmax}=6.64$.

\section{1) Detection of rows with anomalous measurements}

In order for any row with 6 measurements $Z=\left[Z_{1}, Z_{2}, Z_{3}, Z_{4}, Z_{5}, Z_{6}\right]$ in the database of a transmission line be acceptable, it will be necessary that the $J$ value of the row be less than 11.35 [1], [2], [5]. According to this, the Detection of any row of the database with anomalous measurements occurs when $\mathrm{J}>11.35$ occurs in the row.

2) Identification and correction of anomalous measurements

It is known that to solve the system of equations of the transmission line, redundancy is needed $(\mathrm{Nm}>\mathrm{Ns})$, that is 4,5 or 6 measurements are needed.

If any row with anomalous Measurements have been detected (i.e. with $\mathrm{J}>11.35$ ), the anomalous measurements will be identified with the following procedure [2], [5]:

First, in the detected row, the measurement that corresponds to the greatest of the 6 addends of error $\mathrm{J}$ is eliminated because it is suspicious of anomaly.

Then the Estimation process is carried out using the remaining 5 measurements and $\mathrm{J}$ is calculated (8).

If $\mathrm{J}<9.21$ is obtained then this confirms that the suspicious measurement is indeed anomalous and its value is replaced by the corresponding estimate. Whereas if $\mathrm{J}>9.21$ means that the suspicious measurement is not anomalous and the same process is performed for the remaining measurements. If another anomalous measurement is detected, it is also canceled, leaving four Measurements and the threshold for the identification will be 6.64. If three anomalous measurements are detected there will no longer be redundancy and therefore the entire row of data will be eliminated.

\section{RESULTS}

The proposed method has been applied to the $220 \mathrm{kV}$ Chimbote-Trujillo line. This application corresponds to data from July 2018 [6]. The detail of the results of the application of the process, row by row, is shown in Table 2 which corresponds to a subset of 21 data vectors from a total of 2880 data vectors to which this method was applied.

$17^{\text {th }}$ LACCEI International Multi-Conference for Engineering, Education, and Technology: "Industry, Innovation, And Infrastructure for Sustainable Cities and Communities", 24-26 July 2019, Jamaica. 
TABLE 2

APLICATION OF THE DETECTION, IDENTIFICATION AND CORRECTION PROCESS

\begin{tabular}{|c|c|c|c|c|c|c|c|c|c|c|c|c|c|c|}
\hline \multicolumn{4}{|c|}{ SE. CHIMBOTE } & \multicolumn{3}{|c|}{ SE. TRUJILLO } & \multirow{2}{*}{\multicolumn{2}{|c|}{$\mathrm{Ja}$}} & \multirow[b]{2}{*}{ dd } & \multirow{2}{*}{\multicolumn{2}{|c|}{ |OR1 }} & \multirow[b]{2}{*}{ C2 } & \multirow[b]{2}{*}{ OR2 } & \multirow[b]{2}{*}{ ES2 } \\
\hline & MWh & MVARh & $\mathrm{kV}$ & MWh & MVAR & kV & & & & & & & & \\
\hline 1 & 22.34 & 1.089 & 228 & 21.68 & -0.06 & 225 & 3 & 30.0 .1 & 130 & & 0225 & 0 & 0.00 & 0.00 \\
\hline 2 & 22.47 & -1.254 & 227 & 21.38 & -0.06 & 225 & & $\begin{array}{lll}30 & 0.5\end{array}$ & 516 & & 0225 & 0 & 0.00 & 0.00 \\
\hline 1 & 21.62 & -1.386 & 227 & 21.35 & -0.08 & 225 & & 300.0 & 046 & & 0225 & 0 & 0.00 & 0.00 \\
\hline 4 & 20.76 & -1.452 & 227 & -20.66 & -0.11 & 225 & & 300.6 & 087 & & 0225 & 0 & 0.00 & 0.00 \\
\hline J1 & 20.20 & -1.320 & 227 & 19.90 & -0.10 & 225 & & 300.6 & 056 & & 02225 & 0 & 0.00 & 0.00 \\
\hline 6 & 20.63 & -1.353 & 227 & -20.23 & -0.10 & 224 & 3 & 300. & 056 & & 0224 & 0 & 0.00 & 0.00 \\
\hline 71 & 20.69 & -1.617 & 226 & -20.33 & -0.11 & 224 & 3 & 300.6 & 038 & & 0224 & 0 & 0.00 & 0.00 \\
\hline 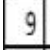 & 21.65 & -1.386 & 226 & -19.07 & 0.10 & 224 & 3 & $\begin{array}{lll}30 & 4.5 \\
\end{array}$ & 596 & & 0224 & 0 & 0.00 & 0.00 \\
\hline 0 & 23.03 & -1.584 & 226 & -22.65 & -0.06 & 223 & 3 & 300.6 & 021 & & 0223 & 4 & -18.58 & -22.65 \\
\hline 10 & 23.60 & $-1,617$ & 225 & -23.19 & -0.08 & 222 & 4 & $\begin{array}{llll}30 & 0.0\end{array}$ & 015 & & 0222 & 4..- & $-19,64$ & -23.19 \\
\hline 11 & 24.82 & -1.353 & 227 & -24.38 & -0.05 & 224 & 3 & 300.6 & 019 & & 0224 & & -19.64 & $-24,38$ \\
\hline 12 & $25.91]$ & -2.640 & 223 & -25.42 & -0.08 & 221 & 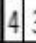 & 300.6 & 002 & & $0 \mid 221$ & $4]^{-}$ & -19.57 & -25.42 \\
\hline 13 & 26.40 & -2.508 & 224 & -25.90 & -0.07 & 222 & 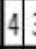 & $\begin{array}{llll}30 & 0.0\end{array}$ & 001 & & 0222 & & -19.44 & -25.90 \\
\hline 14 & 19.43 & -3.168 & 223 & - 19.14 & -0.07 & 222 & 3 & 300.6 & 003 & & 0222 & te & 26.86 & 19.43 \\
\hline 15 & 19.20 & -2.904 & 224 & -18.91 & -0.08 & 223 & 5 & 300. & 008 & & 02223 & & 27.85 & 19.20 \\
\hline 16 & 27.36 & -2.706 & 224 & -26.82 & -0.08 & 222 & & 300.6 & 006 & & 0222 & & -19.07 & -26.82 \\
\hline 17 & 27.49 & -2.046 & 225 & -26.95 & -0.08 & 222 & & 300. & 000 & & 0222 & - & -19.31 & -26.95 \\
\hline 18 & 27.56 & -2.310 & 225 & -27.01 & -0.10 & 222 & & $\begin{array}{llll}30 & 0.5\end{array}$ & 002 & & 0222 & & -19.40 & -27.01 \\
\hline 19 & 27.52 & -2.640 & 224 & -26.98 & -0.08 & 221 & & 300.0. & 007 & & 0221 & $\rightarrow$ & -19.24 & -26.98 \\
\hline 20 & 28.45 & -2.508 & 222 & -27.86 & -0.07 & 219 & & 300.6 & & & 0219 & & -19.04 & -27.86 \\
\hline
\end{tabular}

In this table, the first 6 columns show the measurements with their values already corrected.

Ja, Jd: Estimation errors before and after the correction of the row.

$\mathrm{C} 1, \mathrm{C} 2$ : number of columns of where values were corrected

OR1, OR2: original values in the columns indicated

ES1, ES2: estimated values in the indicated columns

In all the rows, column $\mathrm{C} 1$ indicated that column 6 has been corrected, column OR1 show that the original values were 0 and column ES1 shows the new estimated values.

In rows 10 to 14 and 17 to 21 , column $\mathrm{C} 2$ indicates that column 4 (MWh in Trujillo) has been corrected, column OR2 shows the original values and column ES2 shows the new estimated values.

In rows 15 to 16 , column $\mathrm{C} 2$ indicates that column 1 (MWh in Chimbote) has been corrected, column OR2 shows the original values and column ES2 shows the new estimated values.

\section{CONCLUSIONS}

a) For quality control to be viable, it is important to have full Measurements of active, reactive power and voltages in each bar in the 2880 measurements vectors. In addition, these measurements must be of good quality, so those responsible for the transmission system must provide for the proper maintenance of each link in the chain of processes that involves high voltage measurements.

b) The proposed method is based on techniques of identification of physical parameters and state estimation that configure the state of the art in this type of applications [7-8]

c) The method shows how anomalous measurements of each measurement vector in the Chimbote - Trujillo line are detected, identified and reconstructed. This is very important because in this way those responsible for the lines will be able to detect in which part of the measurement process the errors are occurring.

d) Also in Table 2 the efficiency of the proposed method is confirmed since in many rows it is observed that the optimal estimation error J, severely decreases from very high values $\mathrm{Ja}=30$ (before the process of detection, identification and correction of anomalous measurements) to very small Jd values of the order of hundredths, after the optimal correction.

\section{REFERENCES}

[1]. G. Kusic, "Computer Aided Power Systems Analysis"; Prentice Hall, 1986.

[2]. A. Wood, "Power Generation Operation and Control"; John Wiley, 2013.

[3]. A. Debs, "Estimation of Steady State Power System Model Parameters"; Georgia Institute of Technology, 1974.

[4]. F. Schweppe, "Static State Estimation in Electric Power Systems"; MIT Cambridge, 1974.

[5]. J.J. Grainger, W.D. Stevenson Jr, “Analysis of Power Systems”; Mc. Graw Hill, 1995

[6]. F. Cabezas, "Determinación y Evaluación de Pérdidas de Potencia y Energía en el Sistema Nacional de Transmisión Eléctrica usando Técnicas de Estimación de Estado y de Parámetros Físicos”, Master Thesis, Lima, Perú, 2018.

[7]. FK. Tuffner, TL Williams, "Improving Distribution Resiliency with Microgrids and State and Parameter Estimation", U.S. Department of Energy; Pacific Northwest National Laboratory, 2015.

[8]. B. Centindag, "Development of Models and a Unified Platform for Multiphase Load Flow Analysis and Dynamic State Estimation of Large Distribution Systems with Secondary Grids", Université de Montreal École Polytechnique de Montreal, 2016.

[9]. B. Akbal, A. Urkmez "PSO and CSA to Estimate of Parameter in Power Line" IEEE 2013.

[10].C.S. Indulkar, K. Ramalingam "Estimation of Transmission Line Parameters from Measurements" Elsevier, Science Direct 2007.

$17^{\text {th }}$ LACCEI International Multi-Conference for Engineering, Education, and Technology: "Industry, Innovation, And Infrastructure for Sustainable Cities and Communities", 24-26 July 2019, Jamaica. 